\title{
Leaf arrangements are invalid in the taxonomy of orchid species
}

\author{
Anna Jakubska-Busse ${ }^{\text {Corresp., }}{ }^{1}$ ， Elżbieta Żołubak ${ }^{1}{ }^{\text {， Zbigniew Lobas }}{ }^{1}$, Edyta Magdalena Gola ${ }^{2}$ \\ 1 Department of Botany, Institute of Environmental Biology, University of Wroclaw, Wrocław, Polska \\ 2 Department of Developmental Plant Biology, Institute of Experimental Biology, University of Wrocław, Wrocław, Polska \\ Corresponding Author: Anna Jakubska-Busse \\ Email address: anna.jakubska-busse@uwr.edu.pl
}

The selection and validation of proper distinguishing characters are of crucial importance in taxonomic revisions. The modern classifications of orchids utilize the molecular tools, but still the selection and identification of the material used in these studies is for the most part related to general species morphology. One of the vegetative characters quoted in orchid manuals is leaf arrangement. However, phyllotactic diversity and ontogenetic changeability have not been analysed in detail in reference to particular taxonomic groups. Therefore, we evaluated the usefulness of leaf arrangements in the taxonomy of the genus Epipactis Zinn, 1757. Typical leaf arrangements in shoots of this genus are described as distichous or spiral. However, in the course of field research and screening of herbarium materials, we indisputably disproved the presence of distichous phyllotaxis in the species Epipactis purpurata Sm. and confirmed the spiral Fibonacci pattern as the dominant leaf arrangement. In addition, detailed analyses revealed the presence of atypical decussate phyllotaxis in this species, as well as demonstrated the ontogenetic formation of pseudowhorls. These findings confirm ontogenetic variability and plasticity in E. purpurata. Our results are discussed in the context of their significance in delimitations of complex taxa within the genus Epipactis. 


\section{Leaf arrangements are invalid in the taxonomy of orchid species}

2 Anna Jakubska-Busse ${ }^{1, *}$, Elżbieta Żołubak ${ }^{1},{\text { Zbigniew } \text { Lobas }^{1} \text {, Edyta M. Gola }}^{2}$

$3{ }^{1}$ Department of Botany, Institute of Environmental Biology, University of Wrocław, Kanonia 6/8,

4 50-328 Wrocław, Poland (*corresponding author's e-mail: anna.jakubska-busse@uwr.edu.pl)

$5{ }^{2}$ Department of Plant Developmental Biology, Institute of Experimental Biology, Faculty of

6 Biological Sciences, University of Wrocław, Kanonia 6/8, 50-328 Wrocław, Poland

\section{Abstract}

8 The selection and validation of proper distinguishing characters are of crucial importance in

9 taxonomic revisions. The modern classifications of orchids utilize the molecular tools, but still

10 the selection and identification of the material used in these studies is for the most part related to

11 general species morphology. One of the vegetative characters quoted in orchid manuals is leaf

12 arrangement. However, phyllotactic diversity and ontogenetic changeability have not been

13 analysed in detail in reference to particular taxonomic groups. Therefore, we evaluated the

14 usefulness of leaf arrangements in the taxonomy of the genus Epipactis Zinn, 1757. Typical leaf

15 arrangements in shoots of this genus are described as distichous or spiral. However, in the course

16 of field research and screening of herbarium materials, we indisputably disproved the presence of

17 distichous phyllotaxis in the species Epipactis purpurata Sm. and confirmed the spiral Fibonacci

18 pattern as the dominant leaf arrangement. In addition, detailed analyses revealed the presence of

19 atypical decussate phyllotaxis in this species, as well as demonstrated the ontogenetic formation

20 of pseudowhorls. These findings confirm ontogenetic variability and plasticity in E. purpurata.

21 Our results are discussed in the context of their significance in delimitations of complex taxa

22 within the genus Epipactis.

23 Introduction 
24 Understanding plant variability and the underlying genetic and developmental mechanisms are

25 fundamental to modern plant classifications (Batista \& Bianchetti, 2002; Jones \& Clements, 26 2002; Rudall \& Bateman, 2002; Bateman, Rudall \& Moura, 2013). Genotypic and phenotypic

27 variations reflect the adaptation of a plant to diverse and often demanding environments, and are

28 generally accepted as driving forces behind speciation (Stace, 1991). The family Orchidaceae has

29 recently been extensively studied in attempt to find the phylogenetic relationships within this

30 family (Byng et al., 2016). Although some orchid taxa have been revised based on molecular

31 markers (e.g. Tranchida-Lombardo et al., 2011; Bateman, Rudall \& Moura, 2013; Fajardo, de

32 Almeida Vieira \& Molina, 2014; Zhao, Tang \& Bi, 2017), there is still a lack of consensus

33 regarding the delimitation of other genera (Byng et al., 2016). Specifically, as yet there are no

34 well-defined genetic markers for orchids which would enable the separation of e.g., aggregate

35 taxa (Chung \& Chung, 2012; Fajardo, de Almeida Vieira \& Molina, 2014), especially regarding

36 their phenotypic variability (Jakubska-Busse et al., 2017). Furthermore, the validation of the

37 correct identification of plant materials for genetic analyses is mostly based on morphological

38 traits. Therefore, taxonomic surveys focus mostly on flower and especially column

39 (gynostemium) structure, acknowledged as the most reliable and stable characteristics in orchid

40 classifications being related to the pollination systems (Mered'a, 1999; Szlachetko \& Rutkowski,

41 2000; Lovisa, Verola \& Antonelli, 2010; Claessens \& Kleynen, 2011; Jin et al., 2014). However,

42 these surveys also include general morphological descriptions which are often used in manuals

43 for the determination of taxa (Dressler, 1993; Szlachetko \& Rutkowski, 2000; Delforge, 2006).

44 One of these characteristics in taxa circumscription is leaf arrangement (e.g. Delforge, 2006);

45 however, detailed data on this aspect in the Orchidaceae is lacking.

46 The phenomenon of regular and periodic patterning of leaves (or other lateral organs) is

47 called phyllotaxis and has drawn the attention of researchers for centuries (e.g. Jean 1994; Adler,

48 Barabé \& Jean, 1997; Reinhardt, 2005; Kuhlemeier, 2007). In the plant kingdom, two major 
49 types of leaf arrangements, whorled and spiral (helical) (Zagórska-Marek, 1985, 1994), are

50 recognised. In whorled phyllotaxis, more than one leaf is simultaneously initiated at the

51 meristem, forming a whorl of leaves in a node. The next whorl is circumferentially displaced so

52 that its elements (leaves) are located in a mid-distance between leaves of the previous whorl. A

53 special whorled leaf arrangement, called decussate phyllotaxis, occurs when two leaves are

54 formed per whorl. This is a common pattern in, for example, the families Lamiaceae and

55 Caryophyllaceae (Rutishauser, 1998; Reinhardt, 2005; Gola \& Banasiak, 2016). Another

56 modification of whorled phyllotaxis is distichy, whereby only one leaf is initiated per whorl, but

57 the next leaf is displaced the half distance around the stem, i.e. $180^{\circ}$, with respect to the previous

58 leaf. As a result, leaves occur in two opposite ranks along the stem. This leaf distribution is

59 typical, for example, of the family Poaceae (Gola \& Banasiak, 2016).

60 In the second major type of leaf arrangement, spiral phyllotaxis, successive leaves are

61 initiated separately at the meristem and can be linked along the stem by a spiral line called the

62 ontogenetic spiral. The spatial configuration (chirality) of the ontogenetic spiral can be either

63 clockwise (S chirality) or counterclockwise (Z chirality) (Zagórska-Marek, 1985). Successive

64 leaves are circumferentially displaced at a stable angular distance (divergence angle) and thus do

65 not overlap (Zagórska-Marek, 1985; Jean, 1994). The most frequent spiral phyllotaxis in the plant

66 kingdom (e.g. Zagórska-Marek, 1985, 1994; Jean, 1994; Adler, Barabé \& Jean, 1997;

67 Rutishauser, 1998) is related to the series of Fibonacci numbers, i.e. 1, 1, 2, 3, 5, 8, ... etc., in

68 which each element is the sum of the two preceding elements. The first number in this series

69 refers to the ontogenetic spiral; however, this is hardly visible in the majority of shoots due to the

70 shortening of internodes between successive leaves. Then the secondary spirals (parastichies),

71 winding towards the apex in both directions, clockwise (S) and counterclockwise (Z), become

72 visible at the stem surface. The most discernible spirals, crossing at right angles or near-right

73 angles, form a contact parastichy pair, represented by the two succeeding numbers of the 
74 phyllotactic series, for example, 1:2 or 2:3 in the Fibonacci pattern (Adler, 1974; Zagórska-

75 Marek, 1985, 1994; Jean, 1994). This formula unequivocally identifies the phyllotaxis of a given

76 shoot (Zagórska-Marek, 1985, 1994).

77 It is generally accepted that the spiral leaf arrangement is a plesiomorphic feature in

78 orchids, whereas distichous phyllotaxis or the presence of only one or two leaves per pseudobulb

79 is an apomorphic trait (Withner, Nelson \& Wejksnora, 1974; Arditti, 1992; Dressler, 1993).

80 Rarely, due to the uneven elongation of internodes, two or more leaves are gathered at the same

81 stem level (Dressler, 1993). In the genus Epipactis, the object of our analysis, leaves are usually

82 reported as distichously arranged, but in some species spiral phyllotaxis can also occur (Dressler,

83 1993; Delforge, 2006; Brullo, D'Emerico \& Pulvirenti, 2013; Byng et al., 2016; Lipovšek,

84 Brinovec \& Brinovec, 2017). Despite this general opinion, accurate data on phyllotaxis in the

85 genus Epipactis suitable for use in manuals is lacking. This knowledge is however useful as the

86 additional indirect confirmation of the species identity, especially during the field work when

87 sometimes plants are available only in the vegetative phase and/or during revisions of the

88 collections of plant specimens (vouchers). Therefore, the aims of our research were to (i) analyse

89 the variability of leaf arrangements in E. purpurata in natural conditions; (ii) and quantify

90 phyllotaxis diversity throughout the European range of the species based on herbarium materials,

91 and thus (iii) to validate the usefulness of leaf arrangements in taxa identification.

\section{Materials and Methods}

93 Long-term field investigations of natural populations of E. purpurata were performed

94 between 2003 and 2016 in permanent research plots in four locations in south-western Poland: in

95 Nieszczyce near Rudna (5132'14.26"N, 16²3'56.26"E), the "Błyszcz" nature reserve near

96 Pątnów Legnicki (51¹5'37.09"N, 16²12'56.95"E), Wałkowa near Milicz (51³0'00.46"N,

$\left.97 \quad 17^{\circ} 18^{\prime} 56.04^{\prime \prime E}\right)$ and Straża near Wińsko (51 $\left.23^{\prime} 51.40^{\prime \prime} \mathrm{N}, 16^{\circ} 45^{\prime} 52.47^{\prime \prime} \mathrm{E}\right)$. In this article, only the

98 results of the analyses carried out in 2015 and 2016 are presented. In addition, relevant specimens 
99 from diverse geographical regions deposited in European herbaria (acronyms abbreviations after

100 Thiers (2017): B, BR, C, FR, G, KTU, M, S, WRSL, Z, ZT), were analysed.

101 Leaf arrangements were analysed in both fresh and voucher specimens using the formula

102 of a contact parastichy pair (Adler, 1974; Zagórska-Marek, 1985, 1994). In addition, a series of

103 transverse sections through the mature vegetative shoots were prepared in order to indirectly

104 confirm the leaf arrangements. At the moment when differences in leaf phyllotaxis became

105 macroscopically visible, inflorescences had already been formed and shoot apical meristems were

106 not available for detailed analyses.

107 For anatomical sectioning, shoot fragments which differed in leaf arrangements were

108 collected and fixed in FAA (a formyl-acetic acid-50\% ethanol mixture). Following dehydration

109 in an increasing series of tertiary butyl alcohols $(50 \%, 70 \%, 90 \%, 96 \%$, and three changes in the

110 pure butanol), the plant material was embedded in Paraplast X-tra (Sigma-Aldrich) and

111 transversely cut, using a rotary microtome (Leica RM2135; Leica Instruments), into 10-20 $\mu \mathrm{m}$

112 sections. Series of these cross sections were then de-waxed and stained with the Alcian blue-

113 Safranin O mixture (1:1 v/v; O’Brien \& McCully, 1981). Sequential digital images were taken

114 using the system: a bright-field microscope Olympus BX 50 - Olympus DP70 camera - Cell^B

115 software (Olympus Optical, Poland). Digital images were processed in Fireworks MX 2004

116 (Macromedia, USA) and Photoshop CS6 (Adobe Systems, USA). Plant images were also taken in

117 the field using Canon EOS 50D and Nikon D5300 cameras.

118 Experimental studies and material sampling were done with the permissions of the Regional

119 Director for Environmental Protection, Nos.: WPN.6400.27.2015.IW.1., WPN.6205.122.2016. IL

120 and WPN 6400.29.2016.IL

\section{Results}

122 In the course of our research, more than 470 ramets of E. purpurata were analysed in

1232015 and 2016 in the field, along with over 800 individual herbarium specimens (Table 1). In the 
124 majority of shoots (1210 shoots, i.e. $94.7 \%$ of all studied ramets), leaves were separately and

125 spirally arranged along the stem (Figs. 1A and 2, Table 1). Their arrangement corresponded to 1:2

126 or $2: 3$ contact parastichy pairs, which are expressions of the main Fibonacci pattern. In the

127 analysed material, the frequencies of both spatial configurations of spiral patterns were similar,

128 with the ontogenetic spiral winding clockwise (S-chirality) in 51.9\% and counterclockwise (Z-

129 chirality) in $48.1 \%$ of cases.

130 In five cases $(<1 \%)$, leaves were initiated in pairs (whorls) and oppositely inserted at the

131 stem. Successive pairs were perpendicular to one another, forming a regular decussate pattern

132 (Figs. 1B and 2, Table 1). In such shoots, two or, rarely, three whorls were present along the stem,

133 while lower cauline leaves (below the decussate pattern) as well as bracts were arranged

134 according to spiral phyllotaxis (Figs. 1B and 3). Interestingly, shoots with both decussate and

135 spiral phyllotaxes were found in the ramets of one genet (Fig. 1B).

136 In several shoots (68 shoots, $5.3 \%$ of all analysed ramets), two or three leaves were

137 gathered close to one another, seemingly at the same level of the stem (Figs. 1C, D and 3, Table

138 1). However, the leaves in such gatherings did not form opposite pairs and, in extreme cases,

139 were distinctly inserted on one side of the stem (Fig. 3). The analysis of their spatial distribution

140 proved that they were arranged according to the spiral Fibonacci pattern, which was continued

141 along the whole shoot (Fig. 1D and E). Thus they were identified as pseudowhorls.

142 Histological analyses of mature shoots representing different phyllotactic patterns showed

143 the arrangement of vascular tissue at the cross sections in relation to the leaf position. Vascular

144 bundles were scattered throughout the cross section and distributed typically of

145 monocotyledonous plants. In shoots with a spiral leaf arrangement, at one side of the stem, below

146 the node, vascular bundles divided, giving rise to the leaf vasculature (leaf trace). These newly

147 divided vascular bundles, at the level of leaf insertion in the node, diverged to the leaf, forming

148 its supply system (Fig. 4B and C). After leaf departure, in the region of the internode, bundles 
149 were again relatively regularly scattered throughout the cross section. In the next node, the

150 successive leaf trace was formed in the stem sector circumferentially distant ca. $137-140^{\circ}$ from

151 the previous leaf (Fig. 4B). This pattern repeated along the stem in relation to the successive

152 leaves.

153 In shoots with decussate phyllotaxis, the leaf trace formation for leaves of one pair

154 occurred simultaneously at opposite sides of the stem (Fig. 4C). Vascular bundles in two facing

155 sectors split and departed, forming the vasculature of a given pair. In the subsequent node, the

156 leaf traces for the next pair were again formed by the splitting of existing bundles, but in

157 perpendicular sectors (Fig. 4C).

\section{Discussion}

159 In taxonomic descriptions of the species belonging to the genus Epipactis, the distichous

160 and/or spiral leaf arrangement is usually cited as a typical pattern (Dressler, 1993; Delforge,

161 2006; Byng et al., 2016). However, during over a decade of research on Epipactis morphology,

162 we found no distichous phyllotaxis. Importantly, it is contradictory to the data commonly used in

163 manuals, where leaf arrangement - spiral or in two opposite rows (distichous), is even sometimes

164 given as an indirect feature to distinguish between or to characterise separate species as well as

165 complex taxa (aggregates), for example, E. atrorubens (Hoff.) Besser, E. tremolsii Pau and E.

166 helleborine (L.) Crantz (Delforge, 2006). Interestingly, in 2016, we discovered an atypical

167 decussate arrangement of leaves in E. purpurata. This prompted us to perform a detailed survey

168 of phyllotaxis in this species. In the course of our research, using the formula of a contact

169 parastichy pair, we indisputably disproved the presence of distichy in E. purpurata and confirmed

170 the prevalence of spiral phyllotaxis as the typical leaf arrangement in this species. The phyllotaxis

171 here was identified as that representing the most common Fibonacci pattern in plants (e.g. Jean,

172 1994; Adler, Barabé \& Jean, 1997; Rutishauser, 1998). This pattern occurred in both spatial

173 configurations with comparable frequency, indicating that the direction of the ontogenetic spiral 
174 in this species is randomly selected, similarly as in other plant species (Gregory \& Romberger,

175 1972; Gómez-Campo, 1974; Zagórska-Marek, 1985, 1994).

176 The only exception to the typical spiral Fibonacci pattern in E. purpurata was the

177 occurrence of the whorled decussate phyllotaxis. The decussate pattern in this species was

178 established based on the circumferential arrangement of leaves and further confirmed by analysis

179 of the vasculature. In monocot shoots, E. purpurata included (Jakubska-Busse et al., 2012), the

180 vascular tissue forms a complicated network of bundles scattered throughout the cross section,

181 which, in a longitudinal view, are inclined and wind spirally towards the apex (e.g. Pizzolato \&

182 Sundberg, 2002; Pizzolato, 2002, 2004). Nevertheless, it is possible to establish the stem sectors

183 in which the subsequent leaf traces are formed. Our results confirm that the arrangement of such

184 stem sectors in E. purpurata was in accordance with the position of the leaf insertion at the stem,

185 showing circumferential displacement in shoots with spiral patterns and a regular opposite

186 arrangement in shoots with decussate phyllotaxis. Importantly, we have never observed the

187 decussate pattern along the entire shoot; rather, it emerged during the development of a particular

188 shoot, as leaves at its base, formed earlier in ontogeny, were separately initiated in a spiral

189 sequence. Similarly, leaves above the decussate pattern, especially in the inflorescence, again

190 represented Fibonacci phyllotaxis. These findings illustrate the repeated ontogenetic transitions

191 between different patterns and indicate the developmental plasticity of the E. purpurata shoots.

192 Phyllotactic transitions are known to occur spontaneously during plant ontogeny along the

193 same axis, and especially during the change of the developmental phase (Gómez-Campo, 1974;

194 Meicenheimer, 1979, 1982; Battey \& Lyndon, 1984; Zagórska-Marek, 1985, 1994; Kwiatkowska,

195 1995; Banasiak \& Zagórska-Marek, 2006; Zagórska-Marek \& Szpak, 2008), as well as being

196 evoked by chemical factors (e.g. Maksymowych \& Erickson, 1977; Meicenheimer, 1981).

197 Among the immediate reasons for phyllotactic pattern transitions are variations in the geometric

198 proportions between the organogenic zone of the meristem, where leaves are initiated, and leaf 
199 primordium size (Zagórska-Marek, 1987; Kwiatkowska, 1995; Zagórska-Marek \& Szpak, 2008;

200 Wiss \& Zagórska-Marek, 2012). In meristems with the relatively wide organogenic zone and 201 small primordia, various arrangements of primordia and thus different phyllotactic patterns are

202 possible, as in magnolia gynoecia (Zagórska-Marek, 1994; Zagórska-Marek \& Szpak, 2008; Wiss

203 \& Zagórska-Marek, 2012), cacti (Gola, 1997; Mauseth, 2004), or capitula of the Asteraceae

204 (Hernandez \& Palmer, 1988; Szymanowska-Pułka, 1994). In contrast, if primordia are relatively

205 large compared to the organogenic zone of the meristem, only limited leaf arrangements are

206 possible, as, for example, in grasses. Therefore, ontogenetic changes in apex geometry and the

207 parameters of growth can affect primordia distribution and cause alterations in phyllotaxis.

208 Interestingly, repeated changes in phyllotaxis due to altered meristem proportions have been

209 proven so far only in two mutants, abphyll in maize (Jackson \& Hake, 1999; Giulini, Wang \&

210 Jackson, 2004) and decussate in rice (Itoh et al., 2012). The increased diameter of the meristems

211 of these mutants in response to an affected cytokinin signalling pathway causes a phyllotaxis

212 transition upon development from the distichy in seedlings to the decussate pattern (Jackson \&

213 Hake, 1999; Giulini, Wang \& Jackson, 2004; Itoh et al., 2012). A similar process is observed in

214 Epipactis: early in ramet development, the spiral pattern is formed, then transformed during

215 growth progression into a decussate leaf arrangement. However, in E. purpurata, this transition is

216 unpredictable and occurs infrequently in populations $(>1 \%)$. It is impossible to reach an

217 indisputable conclusion about the developmental and/or genetic background of this phyllotactic

218 change due to a lack of molecular tools for this species as well as to the rarity of the phenomenon

219 and of the taxon itself. It can however be speculated that, similarly to abphyll and decussate

220 mutants, developmental alterations in meristem size cause the observed phyllotaxis transitions.

221 This can partially be confirmed by the fact that Epipactis shoots with decussate phyllotaxis

222 always undergo a second transition back to the Fibonacci pattern during the change to the

223 generative phase, during which the meristem size and growth parameters of the shoot are known 
224 to be significantly modified (e.g. Kwiatkowska, 2008). Additional evidence for the

225 developmental plasticity of E. purpurata shoots is provided by the formation of pseudowhorls,

226 i.e. gatherings of leaves seemingly located at one level of the stem due to the uneven elongation

227 of internodes between them. Pseudowhorls are typical leaf arrangements in some species of

228 Peperomia and Galium (Kwiatkowska, 1999; Rutishauser, 1999), and may also occur as a result

229 of ontogenetic modifications of shoot growth, as in Anagallis (Kwiatkowska, 1995) and Acacia

230 (Rutishauser, 1999).

231 Conclusions

232 In this article, we prove that in E. purpurata the spiral phyllotaxis is dominant; the

233 presence of distichous leaf arrangement has not been confirmed. We document for the first time

234 the presence of decussate phyllotaxis in E. purpurata, which is a rare exception to the typical

235 spiral leaf arrangement in this species. We aim to draw the attention of orchid taxonomists to the

236 intraspecific as well as the ontogenetic diversity of phyllotaxes in the Orchidaceae. Both

237 phenomena are common in plants; moreover, even when one type of phyllotaxis prevails in a

238 given taxon, it does not exclude the occurrence of other leaf arrangements; thus, the whole

239 spectrum of possible phyllotaxes and their ontogenetic transitions must be considered in the

240 course of taxonomic identification. Our finding of the atypical phyllotaxis is another example of

241 ontogenetic variability in the genus Epipactis. In conclusion, we confirmed that spiral phyllotaxis

242 is typical of E. purpurata and that the presence of other leaf arrangements has no taxonomic

243 significance; this is another illustration of the developmental plasticity of the genus Epipactis.

\section{Acknowledgments}

245 We thank to the Curators and Staff of the herbaria of B, BR, C, FR, G, KTU, M, S, WRSL, Z, ZT

246 for loans of the specimens; and to the Reviewers for valuable comments on the manuscript.

247 References 
248 Adler I. 1974. A model of contact pressure in phyllotaxis. Journal of Theoretical Biology 45:1-79.

249 DOI:10.1016/0022-5193(74)90043-5.

250 Adler I, Barabé D, Jean RV. 1997. A history of the study of phyllotaxis. Annals of Botany 80:

251 231-244. DOI: 10.1006/anbo.1997.0422.

252 Arditti J. 1992. Fundamentals of orchid biology. John Wiley \& Sons.

253 Banasiak AS, Zagórska-Marek B. 2006. Signals flowing from mature tissues to shoot apical 254 meristem affect phyllotaxis in coniferous shoot. Acta Societatis Botanicorum Poloniae 75:113-

255 121. DOI: 10.5586/asbp.2006.014.

256 Bateman RM, Rudall PJ, Moura M. 2013. Systematic revision of Platanthera in the Azorean

257 archipelago: not one but three species, including arguably Europe's rarest orchid. PeerJ 1:e218.

258 DOI: $10.7717 /$ peerj.218.

259 Batista JAN, Bianchetti LB. 2002. A review of Habenaria (Orchidaceae) in Pabst and Dungs'

260 Orchidaceae Brasilienses. Lindleyana 17:75-84.

261 Battey NH, Lyndon RF. 1984. Changes in apical growth and phyllotaxis on flowering and

262 reversion in Impatiens balsamina L. Annals of Botany 54:553-567. DOI:

263 10.1093/oxfordjournals.aob.a086826.

264 Brullo C, D’Emerico S, Pulvirenti S. 2013. Karyological and taxonomical considerations on

265 Epipactis cupaniana sp. nov. (Orchidaceae) from Sicily. Nordic Journal of Botany 31:577-589.

266 DOI: 10.1111/j.1756-1051.2012.01666.x.

267 Byng JW, Chase MW, Christenhusz MJM, Fay MF, Judd WS, Mabberley DJ, Soltis DE,

268 Sennikov AN, Soltis DE, Soltis PS, Stevens PF. 2016. An update of the Angiosperm Phylogeny

269 Group classification for the orders and families of flowering plants: APG IV. Botanical Journal 270 of the Linnean Society 181:1-20. DOI: 10.1111/boj.12385. 
271 Chung MY, Chung MG. 2012. A review of the use of genetic markers in orchid systematics with

272 emphasis on allozymes. Biochemical Systematics and Ecology 41:62-73. DOI:

$273 \quad 10.1016 /$ j.bse.2011.12.012.

274 Claessens J, Kleynen J. 2011. The flower of the European orchid: form and function. Voerendaal:

275 Jean Claessens \& Jacques Kleynen.

276 Delforge P. 2006. Orchids of Europe, North Africa and the Middle East. London: A\&C Black

277 Publishers Ltd.

278 Dressler RL. 1993. Phylogeny and classification of the orchid family. Cambridge: University

279 Press.

280 Fajardo CG, de Almeida Vieira F, Molina WF. 2014. Interspecific genetic analysis of orchids in

281 Brazil using molecular markers. Plant Systematics and Evolution 300:1825-1832.

282 DOI:10.1007/s00606-014-1009-9.

283 Giulini A, Wang J, Jackson D. 2004. Control of phyllotaxy by the cytokinin-inducible response

284 regulator homologue ABPHYL1. Nature 430:1031-1034. DOI: 10.1038/nature02778.

285 Gola E. 1997. Phyllotactic spectra in cacti: Mammillaria species and some genera from Rebutia

286 group. Acta Societatis Botanicorum Poloniae 66:237-257. DOI: 10.5586/asbp.1997.030.

287 Gola EM, Banasiak A. 2016. Diversity of phyllotaxis in land plants in reference to the shoot

288 apical meristem structure. Acta Societatis Botanicorum Poloniae 85:3529. DOI:

$289 \quad 10.5586 /$ asbp.3529.

290 Gómez-Campo C. 1974. Phyllotactic patterns in Bryophyllum tubiflorum Harv. Botanical Gazette

291 135:49-58. DOI: 10.1086/336729. 
292 Gregory RA, Romberger JA. 1972. The shoot apical ontogeny of the Picea abies seedling. I.

293 Anatomy, apical dome diameter, and plastochron duration. American Journal of Botany 59:587-

294597.

295 Hernandez LF, Palmer JH. 1988. Regeneration of the sunflower capitulum after cylindrical

296 wounding of the receptacle. American Journal of Botany 75:1253-1261.

297 Itoh JI, Hibara KI, Kojima M, Sakakibara H, Nagato Y. 2012. Rice DECUSSATE controls

298 phyllotaxy by affecting the cytokinin signaling pathway. The Plant Journal 72:869-881. DOI:

299 10.1111/j.1365-313x.2012.05123.x.

300 Jackson D, Hake S. 1999. Control of phyllotaxy in maize by the abphyll gene. Development $301 \quad 126: 315-323$.

302 Jakubska-Busse A, Proćków J, Górniak M, Gola EM. 2012. Is Epipactis pseudopurpurata

303 distinct from E. purpurata (Orchidaceae)? Evidence from morphology, anatomy, DNA and

304 pollination biology. Botanical Journal of the Linnean Society 170: 243-256. DOI: 10.1111/j.1095-

305 8339.2012.01288.x.

306 Jakubska-Busse A, Żołubak E, Jarzembowski P, Proćków J. 2017. Morphological variability in

307 Epipactis purpurata s. stricto (Orchidaceae) - an analysis based on herbarium material and field

308 observations. Annales Botanici Fennici 54: 55-66. DOI: 10.5735/085.054.0310.

309 Jean RV. 1994. Phyllotaxis. A systemic study in plants morphogenesis. New York: Cambridge

310 University Press. DOI: 10.1017/cbo9780511666933.

311 Jin XH, Ren ZX, Xu SZ, Wang H, Li DZ, Li ZY. 2014. The evolution of floral deception in

312 Epipactis veratrifolia (Orchidaceae): from indirect defense to pollination. BMC Plant Biology

313 14:63. DOI: 10.1186/1471-2229-14-63. 
314 Jones DL, Clements MA. 2002. A review of Pterostylis (Orchidaceae): 2. A new classification of

315 Pterostylis R. Br. (Orchidaceae). Australian Orchid Research 4:64-124.

316 Kuhlemeier C. 2007. Phyllotaxis. Trends in Plant Science 12:143-150. DOI:

317 10.1016/j.tplants.2007.03.004.

318 Kwiatkowska D. 1995. Ontogenetic changes of phyllotaxis in Anagallis arvensis L. Acta

319 Societatis Botanicorum Poloniae 64:319-327. DOI: 10.5586/asbp.1995.041.

320 Kwiatkowska D. 1999. Formation of pseudowhorls in Peperomia verticillata (L.) A. Dietr. shoot

321 exhibiting various phyllotactic patterns. Annals of Botany 83:675-685. DOI:

322 10.1006/anbo.1999.0875.

323 Kwiatkowska D. 2008. Flowering and apical meristem growth dynamics. Journal of

324 Experimental Botany 59:187-201. DOI: 10.1093/jxb/erm290.

325 Lipovšek M, Brinovec T, Brinovec M. 2017. Epipactis helleborine (L.) Crantz subsp. moratoria

326 A. Riechelmann \& A. Zirnsack., a new subspecies of Broad-leaved Helleborine in Slovenia.

327 Hacquetia 16: 13-18. DOI: 10.1515/hacq-2016-0011.

328 Lovisa AGS, Verola CF, Antonelli A. 2010. Reassessing the temporal evolution of orchids with

329 new fossils and a Bayesian relaxed clock, with implications for the diversification of the rare

330 South American genus Hoffmannseggella (Orchidaceae: Epidendroideae). Evolutionary Biology

331 10:177. DOI: 10.1186/1471-2148-10-177.

332 Maksymowych R, Erickson RO. 1977. Phyllotactic change induced by gibberellic acid in

333 Xanthium shoot apices. American Journal of Botany 64:33-44.

334 Mauseth JD. 2004. Giant shoot apical meristems in cacti have ordinary leaf primordia but altered

335 phyllotaxy and shoot diameter. Annals of Botany 94:145-153. DOI: 10.1093/aob/mch121. 
336 Meicenheimer RD. 1979. Relationships between shoot growth and changing phyllotaxy of

337 Ranunculus. American Journal of Botany 66:557-569.

338 Meicenheimer RD. 1981. Change in Epilobium phyllotaxy induced by N-1-naphthylphthalamic

339 acid and $\alpha$-4-chlorophenoxyisobutyric acid. American Journal of Botany 68:1139-1154.

340 Meicenheimer RD. 1982. Change in Epilobium phyllotaxy during reproductive transitions.

341 American Journal of Botany 69:1108-1118. DOI: 10.2307/2443085.

342 Mered'a P. 1999. Kl'úč na určovanie druhow rodu Epipactis Zinn publikovaných z ûzemia

343 Slovenska. Identification key to the species of the genus Epipactis Zinn published from Slovakia.

344 Bulletin Slovenskej Botanickej Spoločnosti 21:131-142.

345 O'Brien TP, McCully ME. 1981. The study of plant structure: principles and selected methods.

346 Melbourne: Termarcarphi Pty Ltd.

347 Pizzolato TD. 2002. Procambial initiation for the vascular system in the shoot of Raddia

348 brasiliensis (Poaceae, Bambusoideae). International Journal of Plant Sciences 163:877-889.

349 DOI: $10.1086 / 342629$.

350 Pizzolato TD. 2004. Procambial initiation for the vascular system in the shoot of Alstroemeria

351 (Alstroemeriaceae, Liliales). International Journal of Plant Sciences 165:11-25. DOI:

$35210.1086 / 380981$.

353 Pizzolato TD, Sundberg MD. 2002. Initiation of the vascular system in the shoot of Zea mays L.

354 (Poaceae). II. The procambial leaf traces. International Journal of Plant Sciences 163:353-367.

355 DOI: 10.1086/339514.

356 Reinhardt D. 2005. Regulation of phyllotaxis. The International Journal of Developmental

357 Biology 49:539-546. DOI: 10.1387/ijdb.041922dr. 
358 Rudall PJ, Bateman RM. 2002. Roles of synorganisation, zygomorphy and heterotopy in floral

359 evolution: the gynostemium and labellum of orchids and other lilioid monocots. Biological

360 Reviews 77:403-441. DOI: 10.1017/S1464793102005936.

361 Rutishauser R. 1998. Plastochrone ratio and leaf arc as parameters of a quantitative phyllotaxis

362 analysis in vascular plants. In: Jean RV, Barabé D, eds. Symmetry in plants. Singapore: World

363 Scientific Publ, 171-212.

364 Rutishauser R. 1999. Polymerous leaf whorls in vascular plants: developmental morphology and

365 fuzziness of organ identities. International Journal of Plant Sciences 160:81-103. DOI:

$36610.1086 / 314221$.

367 Stace CA. 1991. Plant taxonomy and biosystematics. Cambridge: Cambridge University Press.

368 Szlachetko DL, Rutkowski P. 2000. Gynostemia orchidalium I. Helsinki: Finnish zoological and

369 botanical publishing board.

370 Szymanowska-Pułka M. 1994. Phyllotactic patterns in capitula of Carlina acaulis L. Acta

371 Societatis Botanicorum Poloniae 65:229-245. DOI: 10.5586/asbp.2011.043.

372 Thiers B. 2017. Index Herbariorum: A global directory of public herbaria and associated staff.

373 New York Botanical Garden's Virtual Herbarium. Available at

374 http://sweetgum.nybg.org/science/ih/(accessed 22 June 2017).

375 Tranchida-Lombardo V, Cafasso D, Cristaudo A, Cozzolino S. 2011. Phylogeographic patterns,

376 genetic affinities and morphological differentiation between Epipactis helleborine and related

377 lineages in a Mediterranean glacial refugium. Annals of Botany 107:427-436. DOI:

$378 \quad 10.1093 / \mathrm{aob} / \mathrm{mcq} 256$.

379 Wiss D, Zagórska-Marek B. 2012. Geometric parameters of the apical meristem and the quality

380 of phyllotactic patterns in Magnolia flowers. Acta Societatis Botanicorum Poloniae 81:203-216.

381 DOI: 10.5586/asbp.2012.029. 
382 Withner CL, Nelson PK, Wejksnora PJ. 1974. The anatomy of orchids. In: Withner CL, eds. The

383 orchids: scientific studies. New York: Wiley-Interscience, 267-347.

384 Zagórska-Marek B. 1985. Phyllotactic patterns and transitions in Abies balsamea. Canadian

385 Journal of Botany 63:1844-1854. DOI: 10.1139/b85-259.

386 Zagórska-Marek B. 1987. Phyllotaxis triangular unit; phyllotactic transitions as the consequences

387 of the apical wedge disclinations in a crystal-like pattern of the units. Acta Societatis

388 Botanicorum Poloniae 56:229-255. DOI: 10.5586/asbp.2011.043.

389 Zagórska-Marek B. 1994. Phyllotaxic diversity in Magnolia flowers. Acta Societatis

390 Botanicorum Poloniae 63:117-137. DOI: 10.5586/asbp.1994.017.

391 Zagórska-Marek B, Szpak M. 2008. Virtual phyllotaxis and real plant model cases. Functional

392 Plant Biology 35:1025-1033. DOI: 10.1071/FP08076.

393 Zhao Y, Tang M, Bi Y. 2017. Nuclear genetic diversity and population structure of a vulnerable

394 and endemic orchid (Cymbidium tortisepalum) in Northwestern Yunnan, China. Scientia

395 Horticulturae 219:22-30. DOI: 10.1016/j.scienta.2017.02.033.

396 Figure legends

397 Figure 1. Diversity of leaf arrangements in E. purpurata. (A) Typical spiral phyllotaxis; (B) An

398 atypical decussate arrangement of E. purpurata shoots. Leaves are initiated in pairs (indicated by

399 red arrows) which in successive nodes are perpendicular to one another. Note that the lower

400 cauline leaves (indicated by yellow arrows) and bracts are inserted separately at the stem

401 according to the spiral sequence, showing the ontogenetic transitions of the phyllotactic pattern;

402 (C, D) Formation of pseudowhorls. Spirally initiated leaves gather seemingly at one level of the

403 stem due to uneven internode elongation, forming pseudowhorls (indicated by red arrows).

404 However, analysis of the leaf circumferential distribution proves the spiral sequence of leaf 
405 initiation (D). (E) Graphic representation of the leaf arrangement along the shoot presented in $(\mathrm{C}-$

406 D); red and blue lines represent parastichies winding toward the apex (black circle), i.e. from

407 older to younger leaves in two opposite directions: clockwise (S chirality, blue lines) and

408 counterclockwise ( $\mathrm{Z}$ chirality, red lines); successive leaves are numbered, with 1 indicating the

409 youngest leaf/bract and the highest number (13 or 14) indicating the oldest lower cauline leaf.

410 Please note that the two ramets of a single genet presented in (C-D) are characterised by opposite

411 chiralities of the ontogenetic spiral. (F) Developmental aberration in the shoot of E. purpurata.

412 Two leaves differing greatly in size are visible at one level of the stem. Scale bars $5 \mathrm{~cm}$ (A-D)

413 and $3 \mathrm{~cm}(\mathrm{~F})$. 


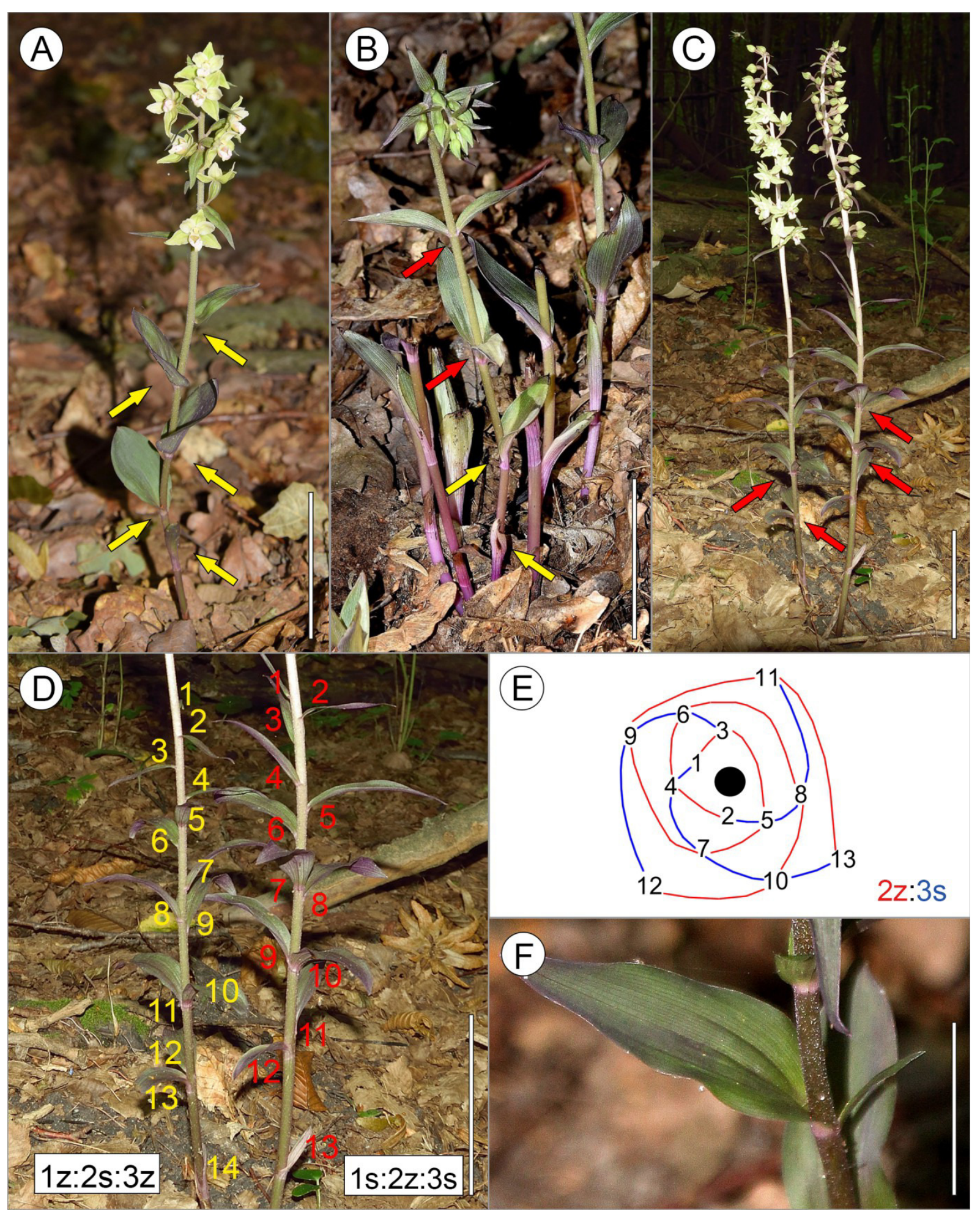


414 Figure 2. Graphic representation of leaf arrangements observed in E. purpurata shoots (drawn by

415 Z. Łobas). (A) Typical spiral distribution of leaves along the stem; (B) Decussate phyllotaxis; (C)

416 Formation of pseudowhorls as a result of leaves gathering at the same stem level due to the

417 limited growth (elongation) of the internode.
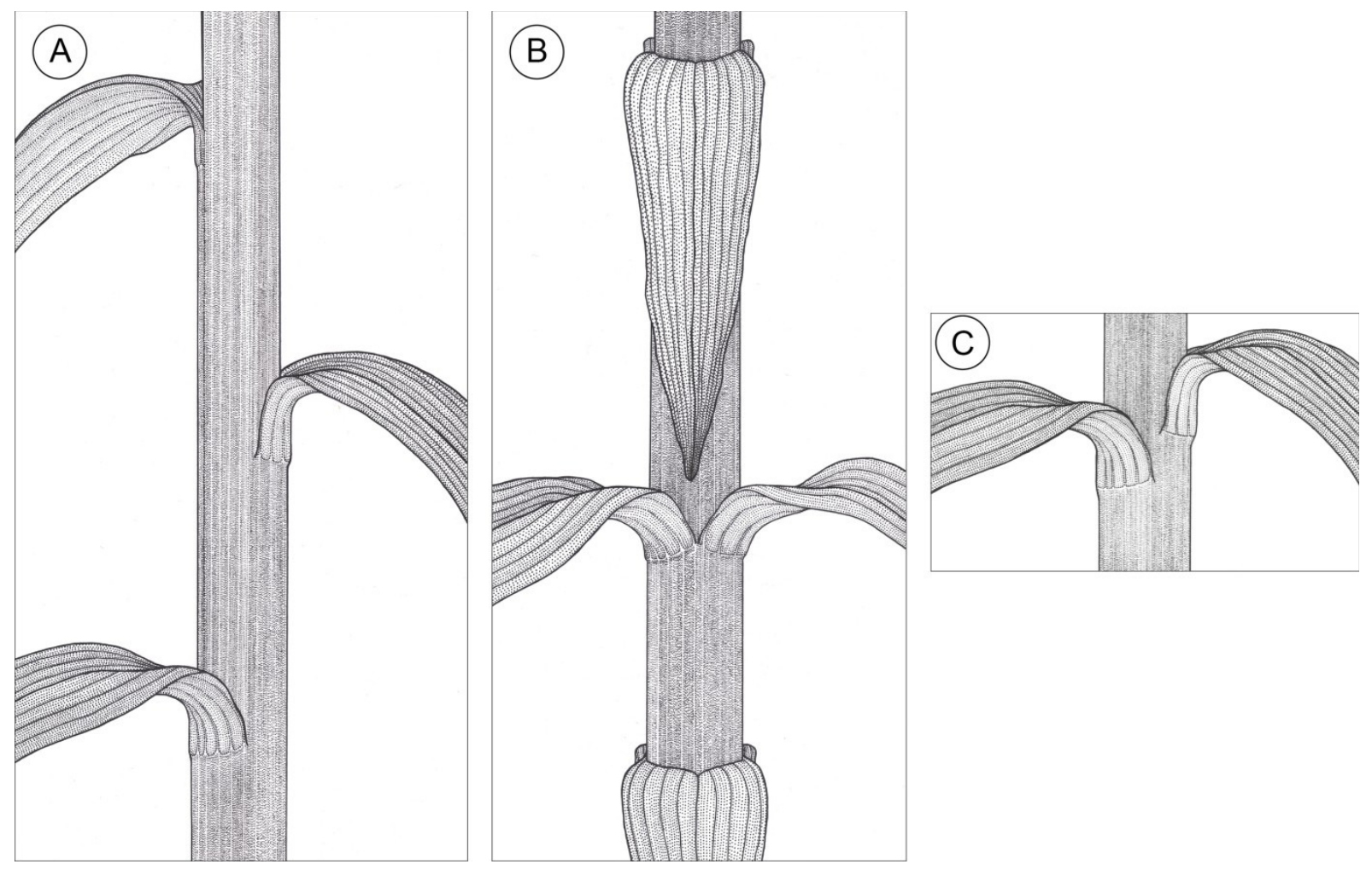
418 Figure 3. Voucher specimens of E. purpurata presenting a number of exemplary abnormalities in

419 leaf arrangement and shoot development. These abnormalities (indicated by filled black

420 arrowheads) include pairs of opposite leaves (A, C, D, F) capable of forming a regular decussate

421 pattern (C), pseudowhorls (B, E), extremely diversified sizes of leaves and split leaf tips (labelled

422 with an asterisk, D), and a bifurcating shoot (F). Typically formed and arranged leaves below and

423 above the nodes with decussate phyllotaxis or pseudowhorls are indicated by clear arrowheads.

424 The acronyms of the herbaria and the voucher numbers are as follows: (A) DK-0005389, (B)

425 DK-0005409, (C) Z-000088596, (D) ZT-00071775, (E) B 10 0591214, (F) FR-0001004. Scale

426 bars $5 \mathrm{~cm}$. 


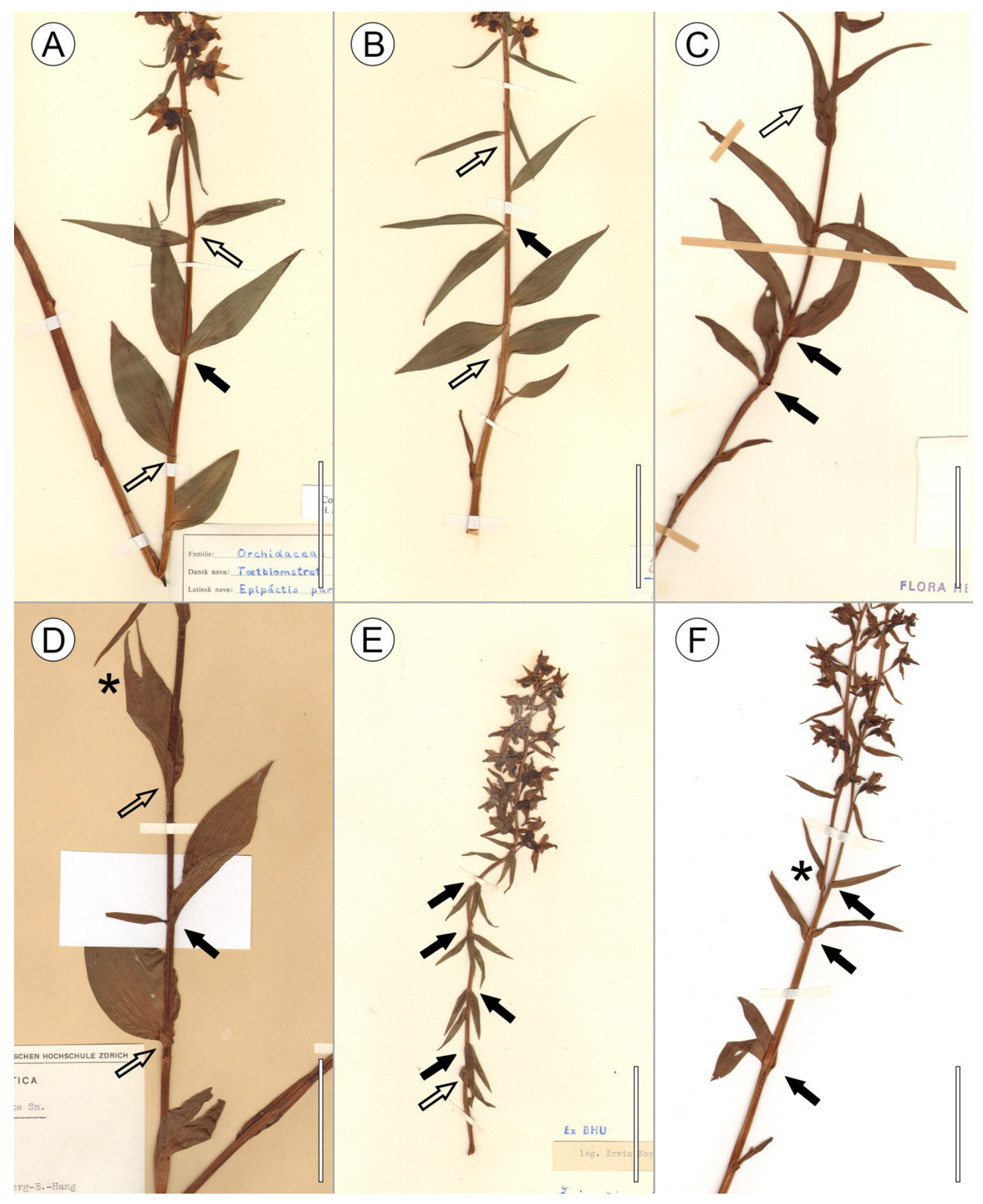


427 Figure 4. Histological analyses of the leaf vasculature in the shoots of E. purpurata differing in 428 phyllotactic patterns. (A-C) Diagrammatic representation (A) of the internode (B), node (C), and 429 corresponding cross sections $(\mathrm{B}, \mathrm{C})$; dashed lines refer to the level of the cross section. Vascular 430 bundles which will be incorporated into the leaf are already split in the internode (B) and visible 431 in the cortical part of the stem. Later, in the node (C), they depart to form the leaf vasculature. 432 (D-G) Vascular structure of a shoot with spiral phyllotaxis. (D) a graphic interpretation of the 433 shoot, viewed from the top, shows the circumferential arrangement of three successively 434 developed leaves (numbered 1, 2, and 3); the angle (circumferential displacement) between them 435 is close to $137.5-140^{\circ}$ and corresponds to the divergence angle for Fibonacci phyllotaxis. The 436 cross sections (E-G) present the same shoot at the levels corresponding to the nodes of three 437 successively developed leaves (numbered 1-3). The positions of successive leaves are marked 438 outside the cross sections as arcs. (H-K) Vascular structure of a shoot with decussate phyllotaxis.

439 (H) a graphic interpretation of the shoot, viewed from the top, shows the circumferential 440 arrangement of two pairs (numbered 1 and 2) of opposite leaves. Leaves of the second pair are 441 circumferentially shifted and located halfway between those of the first pair; as a result, both 442 pairs, the first and the second, are mutually perpendicular. Cross sections (I-K) present the same 443 shoot at the levels corresponding to the nodes of the first and the second pairs (numbered 1 and 2) 444 of opposite leaves and the internode between them. The positions of successive leaf pairs are 445 marked outside the cross sections as arcs. Scale bars (B-C, E-G, I-K) $1000 \mu \mathrm{m}$. 

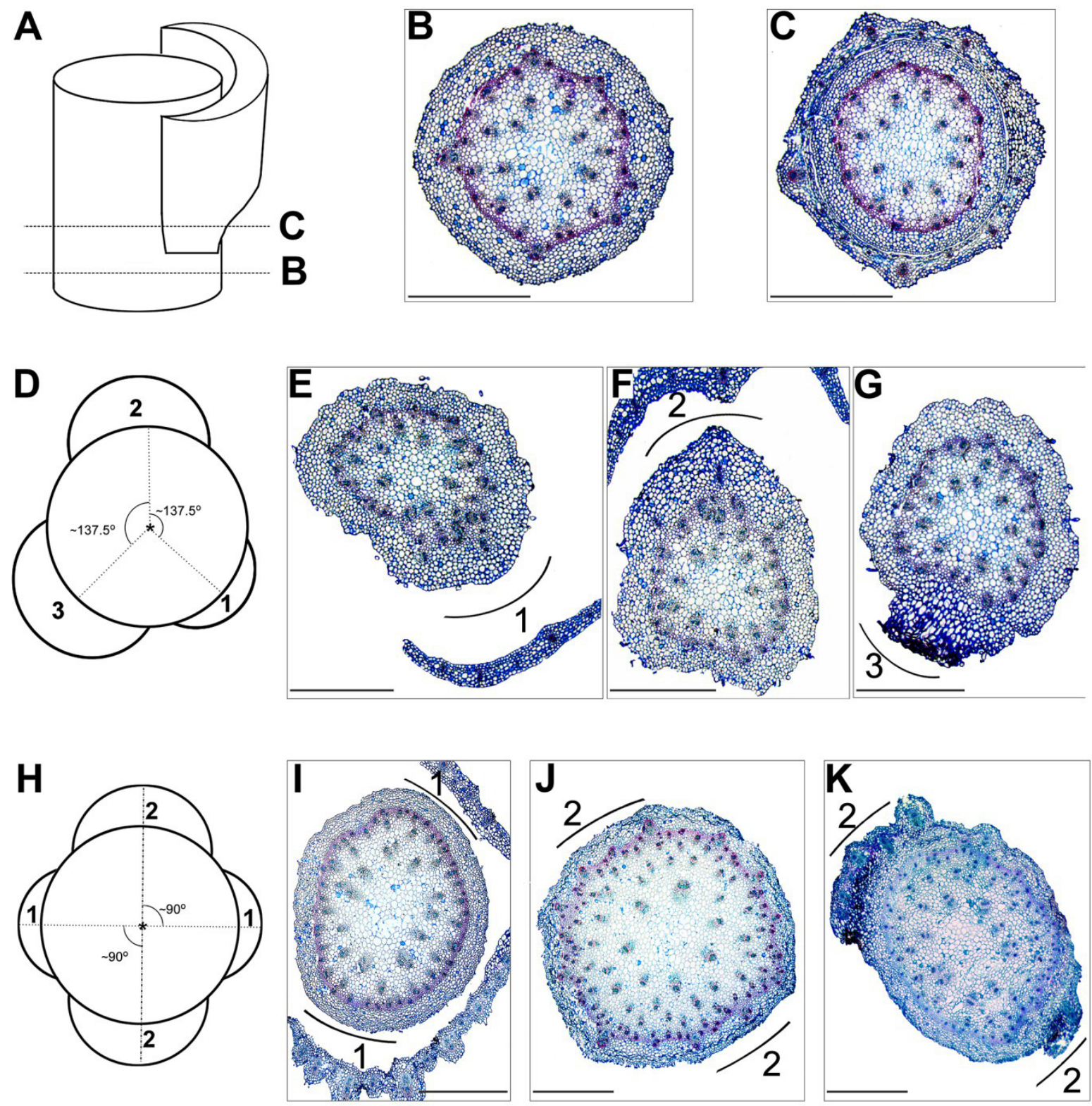
446 Table 1. Leaf arrangements in the material analysed. In a given shoot, more than one phyllotactic

447 pattern can occur, as, for example, in ramets with a decussate pattern (see the text). In the table,

448 for clarity, shoots with abnormal phyllotaxis (decussate pattern or with pseudowhorls) are

449 counted only once within the total amount of ramets analysed. (A) Ramets from SW Poland:

450 Nieszczyce (two cases) and the Błyszcz nature reserve (single case). (B) Phyllotaxis present in

451 specimens from all herbaria analysed. (C) Herbarium voucher specimen details: Z-000088596;

452 ZT-00071819. (D) Voucher specimens with aberrations in leaf arrangements and the acronyms of

453 the herbaria collections are listed in Appendix A.

\begin{tabular}{|c|c|c|c|c|c|c|c|}
\hline & \multicolumn{7}{|c|}{ Leaf arrangement (phyllotaxis) } \\
\hline & & \multicolumn{2}{|l|}{ Spiral } & \multicolumn{2}{|c|}{$\begin{array}{l}\text { Whorled } \\
\text { decussate }\end{array}$} & \multicolumn{2}{|c|}{ Pseudowhorls } \\
\hline & $\begin{array}{l}\text { no. of } \\
\text { ramets }\end{array}$ & $\begin{array}{l}\text { no. of } \\
\text { ramets }\end{array}$ & $\%$ & $\begin{array}{r}\text { no. of } \\
\text { ramets }\end{array}$ & $\%$ & $\begin{array}{l}\text { no. of } \\
\text { ramets }\end{array}$ & $\%$ \\
\hline $\begin{array}{l}\text { Fresh } \\
\text { material }\end{array}$ & 477 & 450 & 94.4 & $3^{A}$ & 0.6 & 24 & 5.0 \\
\hline $\begin{array}{l}\text { Herbarium } \\
\text { vouchers }\end{array}$ & 806 & $760^{B}$ & 94.4 & $2^{C}$ & 0.2 & $44^{\mathrm{D}}$ & 5.4 \\
\hline Total & 1283 & 1210 & 94.7 & 5 & 0.4 & 68 & 5.3 \\
\hline
\end{tabular}

